\title{
Research on the Compensation of Construction Scheme Change in EPC Projects
}

\author{
Tong Zheng \\ Tianjin University of Technology, Tianjin 300384, China \\ zhtong577@163.com
}

Keywords: Construction program, construction integration project procurement, construction (EPC) model.

\begin{abstract}
Because of the particularity of the Engineering-Procurement-Construction (EPC) mode of the integration of design and construction. In the contract, there is no specific definition of the right and responsibility identification after the change of the construction scheme, which leads to a series disputes. In this regard, this paper summarizes three reasons that lead to the change of the construction scheme. On the basis of this, it discusses the compensation for time and cos after the change of construction scheme.
\end{abstract}

\section{Introduction}

In recent years, the change of the construction scheme in the Engineering-ProcurementConstruction (EPC) projects is common, but the solution is not very clear. Usually, when the project has a series of disputes, such as shutdown, change, claim, and so on. The owner and the general contractor will blame each other. In projects, there are many reasons that cause the change of the construction scheme: the contractor optimizes the design1, the force majeure2, the design of the owner's partial change3 and the contractor's construction process does not meet the requirements of the owner4. The division of responsibility after the change of the construction scheme is determined by the party who made the request.

Therefore, by comparing several general contract contracts, this paper identifies the reasons for the change of construction schemes that may result from the owners and general contractors. According to the principle of "who claims to be responsible", analysis of the responsibilities of the contractor and the owner of the project after the change of the construction scheme. On the basis of this, we discuss the compensation issues for both parties.

\section{Situation Analysis and Responsibility Identification}

According to the analysis of related literatures, we summarized three major reasons that caused the change of construction plans: First, the construction scheme change caused by the owner; Second, the construction scheme change caused by the contractors; Third, the construction scheme change caused by the objective factors.

\subsection{Situation Analysis and Responsibility Identification of Owner}

It has been found that the requirements of the owners is a major reason leading to changes in the construction program, but also one of the important reasons that lead to project disputes later. Since the owners in EPC projects do not have the right to control the change of construction scheme. In reality, some reasonable demands made by owners are also somewhat unreasonable. In order to effectively attribution to the change of construction scheme, the "function based" emphasized the "Owner Requirement" in EPC projects. The requirements of the owners lead to changes is divided into two situations: the owner's reasonable request and the owner's subjective requirement.

\subsubsection{Owner's Reasonable Request}

The owner's reasonably requests that the construction scheme be changed. That is, the owner has reason to think that the construction plan must be changed, the owner may require changes construction technology, construction sequence, construction time and so on. 
By comparing the terms of general obligations of the contractor and the owner in Conditions of Contract for EPC/Turnkey and EPC contract text (2011), Clarify the obligations of both parties. The changes in the construction scheme proposed by the owner is summarized as follows:

1. The contractor's construction plan does not meet the contract requirements;

2. The contractor's construction plan does not meet the requirements of the owner in the bidding documents;

3. During the construction, the construction scheme proved to be unfeasible;

4. The construction scheme does not meet the laws and regulations;

5. The project contractor has completed failed to meet the contract requirements, supervision engineers asked for improvement.

Based on the above analysis, the situation that the owner reasonably request the contractor's construction scheme to change. It can be considered that the contractor will breach the contract. The contractor shall bear all the consequences caused by the default. In this case, the owner does not need to extend the period of time and compensate for the cost. If a loss is incurred to the owner, the owner has the right to counterclaim the contractor.

\subsubsection{Owner's Subjective Request}

The owner's subjective request for change of construction scheme means that the owner's behavior interferes with the normal implementation of contractor's construction scheme, and this behavior will bring certain influence to the expected project goal in the future. The changes in the construction scheme proposed by the owner is summarized as follows:

1. The owner changes the "owner's demand" and adjusts the final functional needs of the building;

2. The owner led to accelerated. It includes two cases: presumption and explicit acceleration of construction;

3. The owner led to a suspension of the construction, causing a change in the construction scheme;

4. The owner interferes with the working procedure of the contractor and slows down the construction speed;

5. The owner directives change the construction technology.

In EPC projects, the "owner's demand" change is an engineering change. This change occurs, if the contractor therefore leads to delays or increased costs, the owners should give compensation. The reasons for owner to accelerate or suspend the construction, and therefore incur increased costs or affect the original construction plan. The owner shall give the contractor time and cost compensation. In view of the owner's change in construction sequence or construction technology, which leads to delay in time and increase in cost, whether compensation can be compensated should be analyzed according to specific events. The key to defining the responsibility lies in whether the change of construction sequence or construction technology is reasonable.

\subsection{Situation Analysis and Responsibility Identification of Contractor}

The construction Scheme is usually made by the contractor, according to his own construction drawing design. As long as the functional requirements for the building are finally met, the contractor can adjust it within the limits of authority when constructing, but the Contractor's adjustment needs approval from the owner. The changes in the construction scheme proposed by the contractor is summarized as follows:

1. During construction, the contractor will change the construction scheme due to the repair defects;

2. Construction schedule has (or will) lag behind the plan, the contractor adjusts the construction plan;

3. Adjustment of construction scheme caused by suspension of construction of the contractor;

4. The contractor optimizes the construction plan.

In Conditions of Contract for EPC/Turnkey, stipulate that the contractor will bear almost all the risks. Therefore, all of the above cases belong to the scope of the Contractor's risk, and the owner will no longer extend the duration of the project and compensate for the cost. If this change will bring economic loss to the owners, the owners have the right to claim by the corresponding provisions to safeguard their legitimate rights and interests. 


\subsection{Situation Analysis and Responsibility Identification of Objective Reasons}

The objective reason is the cause of the objective factor. In the project, the objective factor is all the objective facts including the risk factors, except the subjective behavior of the contractor and the owner. The changes in the construction scheme caused by the objective factor is summarized as follows:

1. "Employer's risk" (Force Majeure), causing a change in the construction scheme;

2. Changes in laws and regulations;

3. Changes in the policy;

4. The appearance of site fossils, cultural relics and so on;

5. Unforeseeable difficulties appeared in the process of construction.

In different contract texts, if the change of construction scheme is caused by objective events, the division of responsibilities will be different. It is not all due to the objective cause of the loss of the project can be compensated. It needs to be determined according to the situation. However, in the EPC projects, the contractor has undertaken most of the risks, including all unforeseen difficulties such as accidents and other situations in the construction process.

\section{Study on Compensation for Construction Scheme Change}

\subsection{Time Compensation}

Although EPC is different from other engineering modes in some structural contents, for example, the change of construction scheme, the difference lies in the responsibility identification after the change of construction scheme. However, there is no difference in terms of time or cost of compensation compared to the traditional model.

Among many calculation methods of time compensation, proportional analysis5, planning and actual progress comparison, direct method and actual measurement method are relatively simple and fast, but these methods are not widely applied and have some limitations. Many factors need to be considered when using these methods, but the reality is often not considered comprehensively, resulting in unreasonable and unscientific results, and a large deviation from the actual delay value. Therefore, these methods are not suitable for the time compensation calculation for the actual delay events. Li Zhengzui's6 critical path method and Chenghu's7 network analysis method are relatively practical. They are applicable not only to the time delay caused by all kinds of disturbance events, but also to reflect the actual causes of the actual delays, and the results are scientific and reasonable. So in practice these two methods are usually used to calculate the time compensation.

Not every part of the work delay will cause the total time delay. Only when the delayed work is on the key line of the network diagram, it will cause the total time to be delayed. The principle of time delay compensation calculation is only for the situation of the delayed work on the key line7. When a delay occurs on non-key lines, it is necessary to analyze the network diagram in detail and discuss the free time difference to determine the specific compensation.

\subsection{Cost Compensation}

For the time delay caused by the owner's responsibility, the contractor can not only compensate for the time, but also compensate for the relevant cost. The Contractor's cost compensation follows the principle of actual loss. The actual loss refers to the actual impact of the interference event on the compensation party, mainly the cost, the time and the profit, and the actual impact will be the compensation value. In accordance with the principle, the interest impaired party cannot gain extra benefits or losses due to the project loss.

Cost compensation is a party to which the benefit is damaged requires the other party to compensate for its economic loss or extra expenses. The calculation method is selected according to the conditions of the actual loss of the damaged interests in the project. When the loss is unilateral responsibility, the total cost can be accurately accounted for, but it is difficult to distinguish the specific single item effect, use the total cost method. The basic idea of the total cost method is to take the extra cost of the loss party as the base point and add management fees, the interest and other surcharges as compensation. When there are multiple interference events, and the calculation and method of individual cost are clear, the sub-item method is adopted. The calculation of the sub-item 
method needs to refer to the cost composition of the bid price, and the cost composition of the different projects is different. The domestic compensable items include: labor costs, materials and engineering equipment fees, construction machinery usage fees, measures project costs, business management fees, fees and other additional costs.

\section{Conclusion}

This paper compares a variety of general contracting contracts, starting from the reasons that cause the construction scheme change. Then summarizes three situations of construction scheme changes, and gives the basis for determining the responsibility of various situations. Finally, discussing the contractor's schedule and cost compensation as well as the owner's cost compensation. In the analysis of responsibility recognition, though combined with various contracts, the situation and the type of compensation need to be further complemented.

\section{References}

[1]. Anquan Ma, EPC project application CDB mechanism for change claim analysis in South American, Yunnan hydroelectric power,2015,pp.132-136.

[2]. Zhihui Zhou, Analysis of Yemen Tayizi municipal flood control project 2F project contract claim case, The construction of water conservancy and hydropower,2012,pp.102-103.

[3]. Xuefeng Wang, Analysis of the risk case of EPC project in Africa Garner area, Chemical management, 2016, pp.284:165.

[4]. Yongxin Jiang, Qiang Liu, Yanzhen Bai, Saudi large petrochemical engineering EPC project risk analysis case. Project management technology, 2011, pp.73-78.

[5]. Yan Jian, Calculation of project delay in engineering claims, Construction economy, 1993, pp.31-32.

[6]. Zhengzui Li, Discussion on Contractor's claim under the condition of FIDIC construction contract, Design of hydropower station, 2007, pp. 99-104.

[7]. Hu Cheng, Construction project contract management and claim. (Southeast University press, Nan Jing, 2008), pp.224-285. 